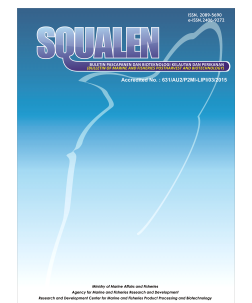

\title{
EFFECT OF HYDROLYZED FUCOIDAN FROM THE BROWN SEAWEED Sargassum binderi SONDER TOWARDS HUMAN BREAST CANCER T47D CELL LINES
}

\author{
Ellya Sinurat ${ }^{*}$, Endang Saepudin ${ }^{2}$, and Fildzah Alfita Qosthalani ${ }^{2}$ \\ ${ }^{1}$ Research Center for Marine and Fiseheries Product Processing and Biotechnology, \\ Jalan KS Tubun Petamburan VI, Slipi, Central Jakarta 10260, Indonesia \\ ${ }^{2}$ Department of Chemistry, Faculty of Mathematics and Natural Sciences, University of Indonesia \\ Article history: \\ Received: 27 April 2017; Revised: 30 June 2017; Accepted: 5 July 2017
}

\begin{abstract}
Fucoidan, a sulfated heteropolysaccharide, consists of L-fucose and sulfate ester groups as the main component. Over the past three decades, fucoidan structures and bioactivities have been widely studied. The chemical components (fucose, galactose, small monosaccharides and also the sulfate) and the molecular weights of fucoidans from different brown seaweed species produce different characteristics and structures of fucoidan. The activity of fucoidan against cancer cells has been reported to be affected strongly by their sulfate content and molecular weight. Low-molecular-weight fucoidans tend to have higher solubility and easily penetrate into cancer cells. The objective of this study was to investigate the effect of hydrolyzed of fucoidan on its anti cancer activity againts the breast cancer T47D cells. In this study, the fucoidan from the brown seaweed Sargassum binderi Sonder was extracted using $0.1 \mathrm{~N} \mathrm{HCl}$ and was depolymerized by acid hydrolysis at various times and concentrations. Result showed that fucoidan hydrolyzed with $1 \mathrm{M}$ trifluoroacetic acid (TFA) for 1.5 hours reached the maximum depolymerization process and resulted in the decrement of molecular weight from $785.12 \mathrm{kDa}$ to $5.79 \mathrm{kDa}$ as well as sulfate content from $18.63 \%$ to $8.69 \%$. The $\mathrm{IC}_{50}$ values of fucoidan and low molecular weight fucoidan against the breast cancer T47D cells were $60.03 \mu \mathrm{g} / \mathrm{mL}$ and $182.34 \mu \mathrm{g} /$ respectively. This result indicated that the sulfate content of fucoidan probably affected its anticancer bioactivities.
\end{abstract}

Keywords: fucoidan, hydrolysis, brown seaweed, sulfate, anticancer

\section{Introduction}

Brown seaweed has long been utilized in the industrial field as a source of iodine, minerals, fatty acids, and vitamins (Kim, 2011). Nowadays, brown seaweed has shown a great potential in producing bioactive compounds as new candidates for medicinal uses (Hayes, 2012). Fucoidan is a polysaccharide mostly found in brown seaweed and contains significant amounts of L-fucose with sulfate ester groups. In contrast to other polysaccharides, fucoidan has shown variation in monomer arrangement and sulfate group distribution among different species of brown seaweed. The structural characteristics of fucoidan are likely dependent on the extraction techniques (Bilan et al., 2010; Ponce et al., 2003), seaweed species, harvesting season (Honya, Mori,
Anzai, Araki, \& Nisizawa, 1999), geographic location (Rioux, Turgeon, \& Beaulieu, 2007), and algal maturity (Zvyagintseva et al., 1999). These factors contribute to the fact that fucoidan structure is complex (Shevchenko et al., 2015). Apart from its complex structures, fucoidan has been found to inhibit the growth of cancer cells (Oliver, Ramon, Andreia, \& Tiago, 2017; Vishchuk, Ermakova, \& Zvyagintseva, 2013; Usui, Asari, \& Mizuno., 1980; Isnansetyo et al., 2017).

The molecular weight and the number of sulfate ester groups, rather than the carbohydrate structure in fucoidan, are the two main parameters in determining the biological activity (Haroun-Bouhedja, Ellouali, Sinquin, \& Boisson-Vidal, 2000). To increase the anticancer activity, the low molecular weight of fucoidan tends to have a higher solubility that helps

${ }^{*}$ Corresponding author.

E-mail: ellya_sinurat@yahoo.com 
fucoidan to penetrate into the targeted cells. Also, the high amount of negative charge from the sulfate ester groups will presumably strengthen the interaction sulfate in fucoidan with the protein of the cancer cells. Therefore, to study the inhibition ability of fucoidan towards cancer cells, further research in fucoidan depolymerization should be conducted.

Depolymerizing fucoidan from polysaccharides to oligo- and monosaccharides has been done by several techniques, such as by acid treatment (Karlsson \& Singh, 1999), enzymatic degradation (Yang et al., 2009) and gamma irradiation (Choi \& Kim, 2013). While gamma radiation may be used to depolymerize fucoidan, it requires a sophisticated technology that is too complex for a routine process.

Fucoidan has been widely reported to have an inhibitory activity against cancer cells. The structure and the chemical compositions of fucoidan affect its biological activity. General aspects that influence the fucoidan bioactivity are monosaccharide composition, sulfate content, molecular weight, binding model/ position, and the arrangement of monosaccharide residues. The number of branching sulfate groups also appears to be the key of higher bioactivities fucoidan since it highly affects the negatively charged fucoidan that inhibit the cancer cell proliferation (Oliver, Ramon, Andreia, \& Tiago, 2017). In this study, fucoidan depolymerization was carried out by acid hydrolysis method with trifluoroacetic acid (TFA) at various concentrations and incubation times. This study was focused on the effect of hydrolyzed fucoidan towards the inhibition level of human breast cancer T47D cell lines. We used prepurified fucoidan extracted from the same brown seaweeds Sargassum binderiSonder as reference.

\section{Material and Methods}

\subsection{Material}

The raw material used in this work was dried brown seaweed with the moisture content of $27.92 \pm 0.35 \%$. The brown seaweed (S. binderiSonder) was collected from Lampung, Indonesia. Chemical reagents used were analytical grades and technical grades.

\subsection{Extraction, Prepurification, and Hydrolysis of Fucoidan}

About $100 \mathrm{~g}$ of cleaned and dried $S$. binderi was ground into small pieces and macerated with $500 \mathrm{~mL}$ of a solvent mixture of $\mathrm{MeOH}-\mathrm{CH}_{2} \mathrm{Cl}_{2}-\mathrm{H}_{2} \mathrm{O}(4: 2: 1)$ at room temperature for 3 hours to remove the lipophilic pigments (chlorophyll, fucoxanthin, carotene) and fats. The resulting extract was then treated with $2 \mathrm{~L}$ of 0.1
$\mathrm{N} \mathrm{HCl}(1: 20)(w / v)$ at $p H 4$ and stirred for 6 hours at room temperature. The filtrate was collected and centrifuged at $5,000 \mathrm{rpm}$ for 15 minutes. The filtrate was subsequently neutralized with $0.5 \mathrm{M} \mathrm{NaOH}$, added with $2 \% \mathrm{CaCl}_{2}$ solution and incubated for 3 hours then centrifuged. The filtrate was collected and added to ethanol (1:2) and incubated overnight. The precipitate in the ethanol solution was separated by centrifugation and freeze-dried to obtain crude fucoidan. Prepurification of fucoidan was conducted using a dialysis membrane (Thermo Scientific Slide-A-Lyzer $3.5 \mathrm{kDa}$ ) in a $0.5 \mathrm{M} \mathrm{NaCl}$ solvent and continued with aquabidest for 24 hours. About $50 \mathrm{mg}$ of prepurified fucoidan was hydrolyzed with $5 \mathrm{~mL}$ of TFA solution at various concentrations $(1,2$, and $3 \mathrm{M})$ and incubation times (1.0; 1.5 ; and 2.0 hours) at $121^{\circ} \mathrm{C}$ using autoclave. Finally, the fucoidan solution was neutralized with $0.5 \mathrm{M} \mathrm{NaOH}$ and then freeze-dried to obtain a hydrolyzed fucoidan (modified method of Sinurat et al., 2015). The hydrolysis of fucoidan was conducted in triplicates.

\subsection{Characterization of Prepurified and Hydrolyzed Fucoidan}

\subsubsection{Determination of monosaccharide composition}

The determination of monosaccharide compositions in hydrolyzed fucoidan was performed using HPLC Shimadzu Prominence-20 instrument with a Hi-Plex H column following Sinurat et al. (2015). The fucoidan solution from hydrolysis treatment was spiked with monosaccharide standards (fucose, galactose, rhamnose, xylose, glucose, and mannose) at varying concentrations $(1000,2000,3000,4000$, $5000 \mathrm{ppm}$ ). About $20 \mu \mathrm{L}$ of each sample was injected into the column with a flow rate of $0.6 \mathrm{~mL} / \mathrm{min}$ for 20 minutes using $0.005 \mathrm{M} \mathrm{H}_{2} \mathrm{SO}_{4}$ as eluent.

\subsubsection{FT-IR analysis}

The analysis of fucoidan functional group was performed by mixing $2 \mathrm{mg}$ of prepurified and hydrolyzed fucoidan with $200 \mathrm{mg}$ of $\operatorname{KBr}(1: 100)$. The resulting pellet was scanned with FT-IR (Perkin Elmer Spectrum One) for 128 times at $4000-400 \mathrm{~cm}^{-1}$ range.

\subsubsection{Determination of sulfate content}

The determination of sulfate ester content in fucoidan was performed by $\mathrm{BaCl}_{2}$ - gelatin method. In $2 \mathrm{~mL}$ of $3.5 \mathrm{~N} \mathrm{HCl}, 6 \mathrm{mg}$ of prepurified and hydrolyzed fucoidan were hydrolyzed for 17-18 hours at 105-110 ${ }^{\circ} \mathrm{C}$ (Dodgson \& Price, 1962). Then, $10 \mu \mathrm{L}$ of hydrolyzed fucoidan was placed into the 96-well plate, added with 
$190 \mu \mathrm{L}$ of $3 \% \mathrm{TCA}$ and $50 \mu \mathrm{L}$ of $0.5 \% \mathrm{BaCl}_{2}$ - gelatin. The plate was left for 20 minutes until the barium sulfate ready to be scanned. $\mathrm{Na}_{2} \mathrm{SO}_{4}$ was used as a standard with various concentrations ( $100-500 \mathrm{ppm})$. Both sample and standard solutions were scanned against blank solution in triplicates with Microplate Reader Spectrophotometer at $\lambda=360 \mathrm{~nm}$.

\subsubsection{Determination of total carbohydrate}

The determination of total carbohydrate content was performed by phenol - sulfuric acid method (Dubois Gilles, Hamilton, Rebers, \& Smith, 1956). The prepurified and hydrolyzed fucoidan $(5 \mathrm{mg})$ was dissolved in $1 \mathrm{~mL}$ of aquadest and then $2.5 \mathrm{~mL}$ of concentrated $\mathrm{H}_{2} \mathrm{SO}_{4}$ was added prior to incubation in an ice tub for 30 minutes. Subsequently, $0.5 \mathrm{ml}$ of $5 \%$ phenol was added into the sample solution and was also incubated in the ice tube for 30 minutes. Fucose, mannose, and xylose were used as standards at various concentrations $(200,400,600,800,1000 \mathrm{ppm})$. Sample, standard, and blank solutions were measured in triplicates at $480 \mathrm{~nm}$ and $490 \mathrm{~nm}$ with a UV-VIS spectrophotometer.

\subsection{Anticancer Activity Assay}

\subsubsection{Cell line and culture}

The breast cancer T47D cells from BBRP2BKP collection was cultured in RPMI medium (SigmaAldrich, St. Louis, MO, USA) supplemented with 10\% FBS (Sigma-Aldrich, St. Louis, MO, USA), $2 \%$ penicillin-streptomycin (Gibco, Grand Island, NY, USA), and $0.5 \%$ fungison (Gibco) in an incubator (ESCO Cell Culture) with a humidified $5 \% \mathrm{CO}_{2}$ at $37^{\circ} \mathrm{C}$.

\subsubsection{Growth inhibition assay}

The effect of hydrolyzed and non-hydrolyzed fucoidan on the inhibition of cancer cells was assessed in vitro by MTT assay (Isnansetyo et al., 2017). Prepurified and hydrolyzed fucoidans were respectively dissolved in aquabidest, DMSO, and growth medium into different dosages. Three types of control were also prepared, which are cancer cell control, media control, and sample control. Briefly, human breast cancer T47D cells lines were incubated in 96-well plate $\left(1,5 \times 10^{4} \mathrm{cells} /\right.$ well $)$ until reaching a confluent phase (12-24 hours). After incubation, $100 \mu \mathrm{L}$ of serial dosages of prepurified and hydrolyzed fucoidans were respectively added and incubated for 24 hours in a $\mathrm{CO}_{2}$ incubator. Cells were then added with MTT reagent and incubated for 4 hours. The reaction was stopped with the addition of $10 \%$ SDS and incubated for 12 hours. The cell growth was observed with microscope inverted and absorbance measured in triplicates with Spectrophotometer Microplate Reader at wavelength $570 \mathrm{~nm}$. The inhibition rate was calculated according to the formula:

Inhibition rate $(\%)=\underline{(C-D)-(A-B)}$

$$
(C-D) \quad \times 100 \%
$$

where each absorbance stands for: $A=$ fucoidan samples; $\mathrm{B}=$ control sample; $\mathrm{C}=$ control cells; $\mathrm{D}=$ control media. The $\mathrm{IC}_{50}$ value was calculated by probit analysis.

\section{Results and Discussion}

\subsection{Results}

\subsubsection{Isolation and chemical characteristics of crude and prepurified fucoidan}

The yield of crude fucoidan (CP) obtained from dried brown seaweed S. binderi Sonder was $6.64 \%$. After prepurification with a dialysis membrane $(3.5 \mathrm{kDa}$ cutoff), $1.67 \%$ of prepurified fucoidan (PF) was obtained. The total content of carbohydrates and sulfates in both fucoidan species is shown in Table 1. Crude fucoidan (CF) gave a higher yield than the PF, but has a lower percentage of total carbohydrate $(47.65 \%)$ than PF $(82.79 \%)$. It indicated that the dialysis process has significantly increased the purity of fucoidan. Hydrolysis of prepurified fucoidan decreased the sulfate content and also its molecular weight as shown in Tabel 1.

\subsubsection{Fucoidan depolymerization}

The oligomer and monomer levels are important parameter to determine the optimum hydrolysis of fucoidan. Lowest oligomer level indicates the most optimum hydrolysis function. The fucoidan that hydrolyzed into monomers, as expected, contained a high level of fucose. Since fucose is the major monomer constituent of fucoidan, its level in fucoidan can be used as indicator of the hydrolysis process level. Figure 1 shows the hydrolysis results, whereas Figure 2 shows the monosaccharide content in fucoidan oligomers after hydrolisis treatment. The optimum hydrolysis was achieved using $1.5 \mathrm{~h}, 3 \mathrm{M}$ TFA and 1.5 h, 1M TFA. We consider using hydrolysis using the lower concentration of TFA, for fucoidan hydrolysis i.e $1 \mathrm{M}$ as the best concentration for fucoidan hydrolysis, used for the next study on the basic of economical and reasons.

\subsubsection{Chemical characterization of hydrolyzed fucoidan}

In hydrolysis treatment, most of the chemical characteristics in fucoidan was affected. In Table 1, it 
Table 1. Yield and chemical characteristics of crude and purified fucoidan

\begin{tabular}{lcccc}
\hline \multicolumn{1}{c}{ Fucoidan } & $\begin{array}{c}\text { Yield } \\
(\%)\end{array}$ & $\begin{array}{c}\text { Total Carbohydrate } \\
(\%)\end{array}$ & $\begin{array}{c}\text { Sulfate Content } \\
(\%)\end{array}$ & Mw (kDa) \\
\hline Crude (CF) & 6.64 & $47.65 \pm 1.05$ & $22.99 \pm 0.8$ & 1407.67 \\
Prepurifed (PF) & 1.67 & $82.79 \pm 1.4$ & $18.63 \pm 0.7$ & 785.12 \\
Hydrolyzed Fucoidan & $42 \pm 3.0$ & $55.86 \pm 1.2$ & $8.69 \pm 0.5$ & 5.79 \\
$(1.5 \mathrm{H}-1 \mathrm{M})$ & & & & \\
\hline
\end{tabular}

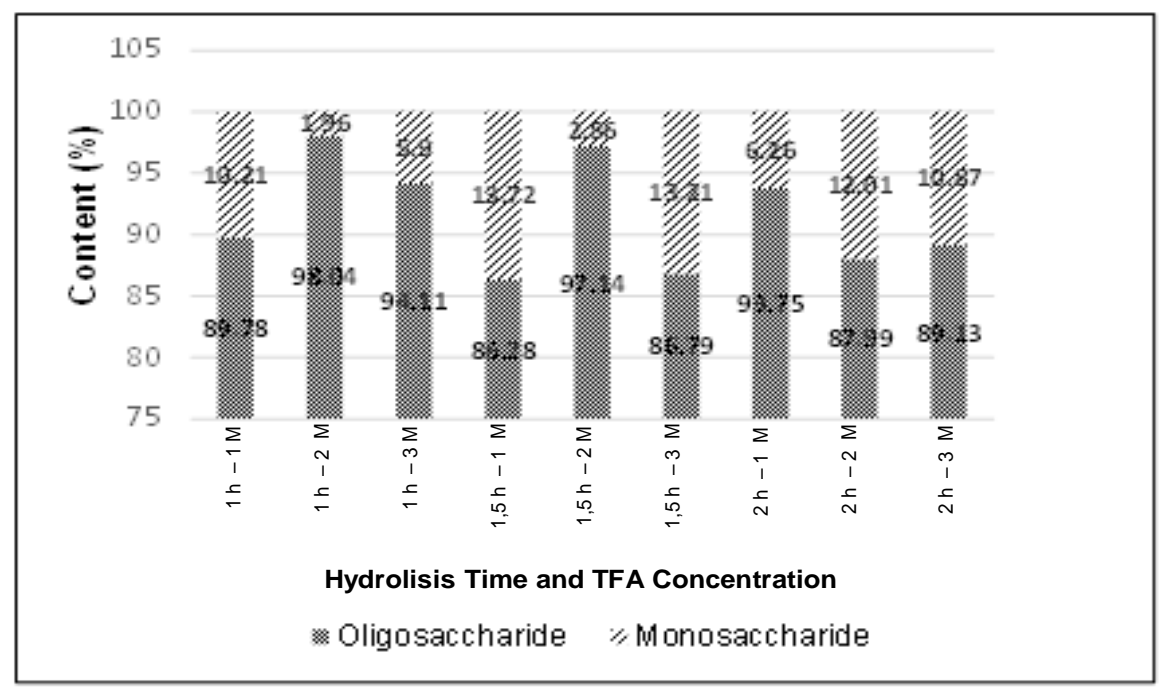

Figure 1. Diagram of fucoidan fragments at various hydrolysis treatment.

is shown that the maximum hydrolysis condition reduced the total carbohydrate and sulfate contents in fucoidan to $55.86 \%$ and $8.69 \%$, respectively. The depolymerization process reduced molecular weight of prepurified fucoidan from $785.12 \mathrm{kDa}$ to $5.79 \mathrm{kDa}$ after hydrolysis.

The monosaccharide composition of fucoidan $S$. binderi Sonder determined by HPLC with the RI detector mainly consisted of fucose and mannose. While in the same brown seaweed species (Sinurat et al., 2015), fucoidan from S. binderi Sonder has been reportedly composed of fucose, galactose, glucose, mannose, xylose, and glucuronic acid (abundance ratio of $1: 2: 4: 1: 1: 2$ ) by the GC-MS method. It was achieved after fucoidan was purified in DEAE resin and hydrolysis in $2 \mathrm{M}$ of TFA for 1 hour. Purification and hydrolysis at high temperature cleaved fucoidan and at such condition, some mono and oligosaccharides may undergo decomposition through the so called caramelization.

\subsubsection{FT-IR analysis}

Result FT-IR analysis of fucoidan showed the presence of sulfate ester groups as well as their binding positions. The wavenumber at $1240-1260 \mathrm{~cm}$
${ }^{1}$ indicates the presence of symmetric sulfate ester group $(\mathrm{O}=\mathrm{S}=\mathrm{O})$, while the asymmetric sulfate ester $(\mathrm{O}-\mathrm{S}=\mathrm{O})$ was detected at $1030-1060 \mathrm{~cm}^{-1}$. In addition, the ester sulfate binding position can be distinguished to axial $\left(840 \mathrm{~cm}^{-1}\right)$ and equatorial (820 $\mathrm{cm}^{-1}$ ) positions (Usov \& Bilan, 2009).

Based on the FT-IR spectra (Figure 3 ) and the detail lists on Table 2, the presence of sulfate ester group in crude and prepurified fucoidan appeared in symmetrical, whereas the sulfate ester group in hydrolyzed fucoidan appeared in axial or equatorial. The binding position also showed a different result, where the prepurified fucoidan appeared in equatorial and the hydrolyzed fucoidan in axial. This FT-IR result illustrates that acid hydrolysis treatment might affect the sulfate ester group conformation that potentially influence the bioactivity of fucoidan, i.e, the inhibition against T47D breast cancer cells.

\subsubsection{Cytotoxicity of fucoidan against human breast T47D cancer cell lines}

The anticancer activity of fucoidan against T47D breast cancer cells was assessed by MTT method and was expressed in $\mathrm{IC}_{50}$ values. 


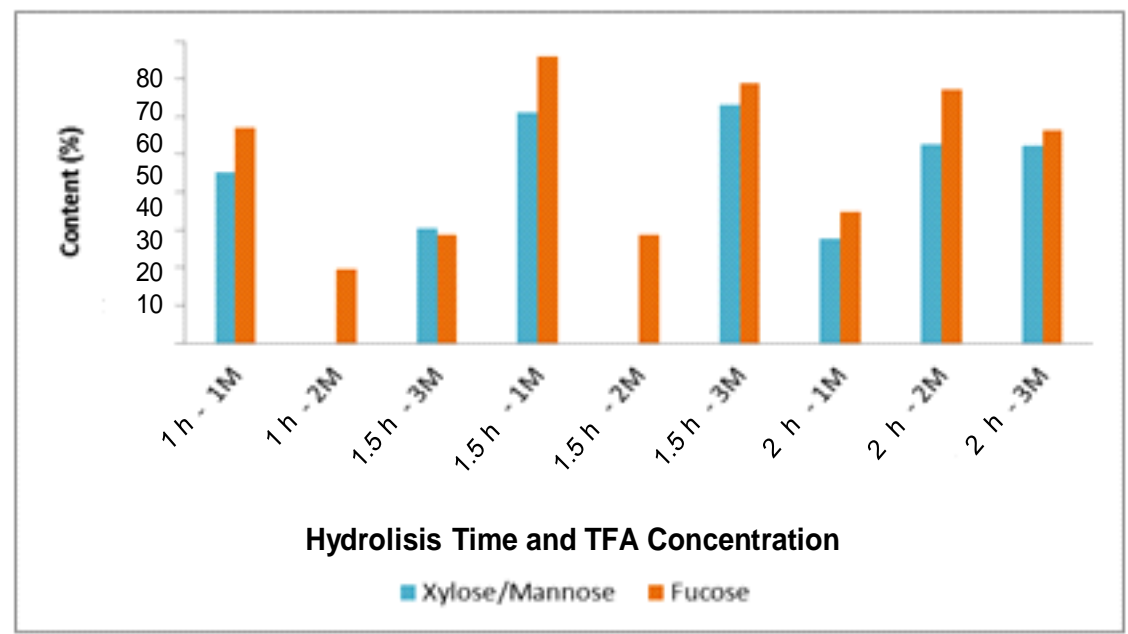

Note: At that condition (1.5 hours incubation, $1 \mathrm{MTFA}$ ) the oligomer level was $86.28 \%$ containing the fucose level of $7.59 \%$.

Figure 2. Diagram of monosaccharides content at various hydrolysis treatment.

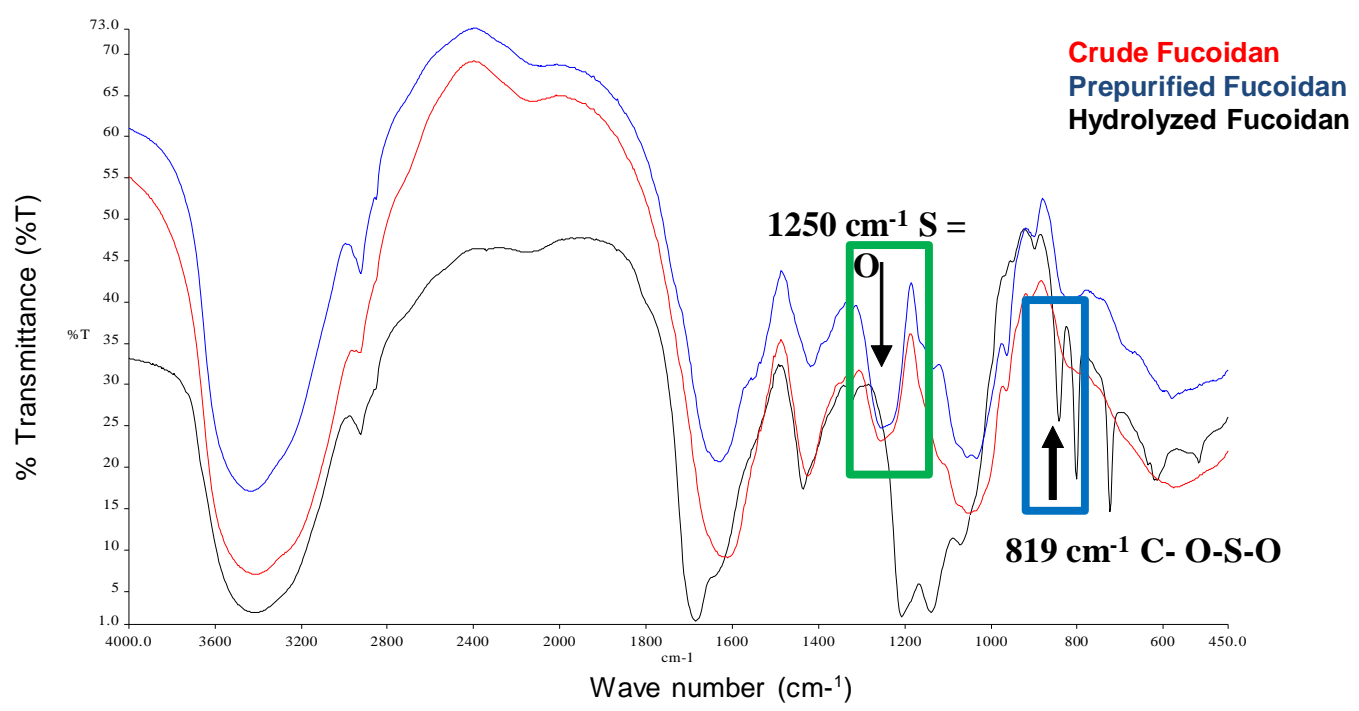

Figure 3. FT-IR spectra of crude fucoidan (red), prepurified fucoidan (blue), and hydrolyzed fucoidan (black).

Table 2. Ester sulfate functional groups of crude, prepurified and hydrolyzed fucoidans

\begin{tabular}{lccc}
\hline \multicolumn{1}{c}{ Functional Group } & $\begin{array}{c}\text { Crude } \\
\text { Fucoidan }\end{array}$ & $\begin{array}{c}\text { Prepurified } \\
\text { Fucoidan }\end{array}$ & $\begin{array}{c}\text { Hydrolyzed } \\
\text { Fucoidan }\end{array}$ \\
\hline Sulfate ester symmetric $(\mathrm{O}=\mathrm{S}=\mathrm{O})\left(\mathrm{cm}^{-1}\right)$ & 1256.22 & 1254.22 & - \\
Sulfate ester asymmetric $(\mathrm{O}-\mathrm{S}=\mathrm{O})\left(\mathrm{cm}^{-1}\right)$ & - & - & 1071.91 \\
Sulfate ester equatorial $\left(\mathrm{cm}^{-1}\right)$ & - & 819.13 & - \\
Sulfate ester axial $\left(\mathrm{cm}^{-1}\right)$ & - & - & 843.12 \\
\hline
\end{tabular}


At a dose of $60.03 \mu \mathrm{g} / \mathrm{mL}$, prepurified fucoidan inhibited $50 \%$ of the viable T47D cells population. Meanwhile, to reach the same result, hydrolyzed fucoidan needed to triple its concentration as those of the prepurified fucoidan $(182.34 \mu \mathrm{g} / \mathrm{mL})$. This result showed that low molecular weight fucoidan produced by hydrolysis treatment was not as cytotoxic as the prepurified fucoidan. It was assumed that the fucoidan was only partially hydrolyzed. The hydrolysis product lower also has a sulfate content $(8.69 \%)$ than that of the prepurifed fucoidan (18.63\%) (Table 1).

Dumitriu (1996) reported that fucoidan with molecular weight ranges of $50-100 \mathrm{kDa}$ performed the highest biological activity, while the higher molecular weight (> $850 \mathrm{kDa}$ ) fucoidan showed lower activity. Depolymerization play a role in the formation of low molecular weight fucoidan (Chevolot et al., 2001). The high molecular weight fucoidan consists of a long-chain polysaccharide. As a result, it will be more difficult to digest, especially by a low living entity such as cancer cells (Shimizu et al., 2005).

In this study, the inhibition rate of prepurified fucoidan was higher than that of the hydrolyzed fucoidan. It indicates that the molecular weight of fucoidan was not the only factor that affects the cytotoxicity of fucoidan. During depolymerized process by acid hydrolysis, the fucoidan showed a massive reduction in its molecular weight from 785.12 $\mathrm{kDa}$ to $5.79 \mathrm{kDa}$. The sulfate ester group attached to fucoidan might have been also reduced and caused a decreasing concentration of sulfate content. In this case, the hydrolyzed fucoidan contained a lower sulfate content that might cause to a lower inhibition rate to T47D breast cancer cells compared to that of the prepurified fucoidan. Based on this study, the sulfate content has an important role in the fucoidan cytotoxic activity againts T47D breast cancer cells.

\section{Conclusion}

The prepurified fucoidan inhibited $50 \%$ of T47D breast cancer cells with lower dosage $(60.03 \mu \mathrm{g} / \mathrm{mL})$ than that of the hydrolyzed fucoidan $(182.34 \mu \mathrm{g} / \mathrm{mL})$. The sulfate content of fucoidan might play a significant role for its bioactivity as anticancer.

\section{Acknowledgements}

The authors thank Dr. Muhammad Nursid for his helpful assistance for anticancer activity assay

\section{References}

Bilan, M.I., Grachev, A.A., Shashkov, A.S., Kelly, M., Sanderson, C.J., Nifantiev, N.E., \& Usov, A.I. (2010). Further studies on the composition and structure of a fucoidan preparation from the brown alga Saccharina latissima. Carbohydrate Research, 345(14), 2038-2047. https://doi.org/10.1016/j.carres. 2010.07.009

Chevolot, L., Mulloy, B., Ratiskol, J., Foucault, A., \& Colliec-Jouault, S. (2001). A disaccharide repeat unit is the major structure in fucoidans from two species of brown algae. Carbohydrate Research, 330(4), 529-535.https://doi.org/10.1016/S0008-6215(00) 00314-1.

Choi, J.Il., \& Kim, H.J. (2013). Preparation of low molecular weight fucoidan by gamma-irradiation and its anticancer activity. Carbohydrate Polymers, 97(2), 358-362. https://doi.org/10.1016/j.carbpol. 2013. 05.002 .

Dodgson, K.S., \& Price, R.G. (1962). A note on determination of the ester sulphate content of sulphated polysaccharides. Biochem. J., 84(1): 106110.

Dubois M., Gilles, K.A., Hamilton, J.K., Rebers P.A., \& Smith, F. (1956). Colorimeter method for determination of sugars and related subtances. Analytical Chemistry 28, 350-356.

Dumitriu, S. (1996). Polysaccharides in Medicinal Applications. Taylor \& Francis. Retrieved from https:/ /books.google.co.id/books?id=bERzs5eztYMC

Haroun-Bouhedja, F., Ellouali, M., Sinquin, C., \& BoissonVidal, C. (2000). Relationship between sulfate groups and biological activities of fucans. Thrombosis Research, 100(5), 453-459. https://doi.org/10.1016/ S0049-3848(00)00338-8.

Hayes, M. (2012). Marine Bioactive Compounds. (M. Hayes, Ed.). Springer New York Dordrecht Heidelberg London. https://doi.org/10.1007/978-1-4614-1247-2

Honya, M., Mori, H., Anzai, M., Araki, Y., \& Nisizawa, K. (1999). Monthly changes in the content of fucans, their constituent sugars and sulphate in cultured Laminaria japonica. Hydrobiologia, 398(0), 411-416. https://doi.org/10.1023/A:1017007623005.

Isnansetyo, A., Nor, F., Lutfia, L., Nursid, M., Susidarti, R. A., \& Isnansetyo, A. (2017). Cytotoxicity of fucoidan from three tropical brown algae against breast and colon cancer cell lines, Pharmacognosy Journal,2 9(1), 14-20. DOI:10.5530/pj.2017.1.3.

Karlsson, A., \& Singh, S. (1999). Acid hydrolysis of sulphated polysaccharides. Desulphation and the effect on molecular mass. Carbohydrate Polymers, 38(April 2016), 7-15. https://doi.org/10.1016/S01448617(98)00085-X. 
Kim, S. K. (2011). Handbook of Marine Macroalgae: Biotechnology and Applied Phycology. Wiley.

Oliver, C., Ramon, N-C., Andreia, S, F., \& Tiago, H.S. (2017). The key role of sulfation and branching on fucoidan antitumor activity., Macromolecular Bioscience. 17(5) 13, doi:10.1002/mabi.201600340.

Ponce, F. A., Srinivasan, S., Bell, A., Geng, L., Liu, R., Stevens, M., ... Tanaka, S. (2003). Microstructure and electronic properties of InGaN alloys. Physica Status Solidi (B), 240(2), 273-284. https://doi.org/10.1002/ pssb.200303527.

Rioux, L.E., Turgeon, S.L., \& Beaulieu, M. (2007). Rheological characterisation of polysaccharides extracted from brown seaweeds. Journal of the Science of Food and Agriculture, 87(9), 1630-1638. https://doi.org/10.1002/jsfa.2829.

Shevchenko, N.M., Anastyuk, S.D., Menshova, R.V., Vishchuk, O.S., Isakov, V.I., Zadorozhny, P.A., ... \& Zvyagintseva, T.N. (2015). Further studies on structure of fucoidan from brown alga Saccharina gurjanovae. Carbohydrate Polymers, 121, 207-216. https:// doi.org/10.1016/j.carbpol.2014.12.042.

Shimizu, J., Wada-Funada, U., Mano, H., Matahira, Y., Kawaguchi, M., \& Wada, M. (2005). Proportion of Murine Cytotoxic T Cells is Increased by High Molecular-Weight Fucoidan Extracted from Okinawa mozuku (Cladosiphon okamuranus). Journal of Health Science, 51(3), 394-397. https://doi.org/ 10.1248/jhs.51.394.

Sinurat, E., Saepudin E \& Peranginangin, R. (2015). Purification and characterization of fucoidan from the brown seaweed sargassum binderi sonder, Squalen
Bull. of. Mar. and. Fish. Postharvest and Biotech., 10(2),79-87.https://doi.org/10.15578/squalen. v10i2.133.

Usov A.I \& Bilan M.I. (2009). Fucoidan sulfated polysaccharides of brown algae. Russian Chemical reviews 78 (8), 785-799.

Usui, T., Asari, K., \& Mizuno, T. (1980). Isolation of highly purified fucoidan" from Eisenia bicyclis and Its Anticoagulant and Antitumor Activities. Agricultural and Biological Chemistry, 44(8), 1965-1966. https:// doi.org/10.1080/00021369.1980.10864249.

Vishchuk, O.S., Ermakova, S.P., \& Zvyagintseva, T.N. (2013). The fucoidans from brown algae of FarEastern seas: Anti-tumor activity and structurefunction relationship. Food Chemistry, 141(2), 12111217. https://doi.org/10.1016/j.foodchem. 2013. 03.065 .

Yang, B., Yu, G., Zhao, X., Jiao, G., Ren, S., \& Chai, W. (2009). Mechanism of mild acid hydrolysis of galactan polysaccharides with highly ordered disaccharide repeats leading to a complete series of exclusively odd-numbered oligosaccharides. FEBS Journal, 276(7), 2125-2137. https://doi.org/10.1111/j.17424658.2009.06947.x.

Zvyagintseva, N. T., M Shevchenko, N., B Popivnich, I., V Isakov, V., S Scobun, A., V Sundukova, E., \& A. Elyakova, L. (1999). A new procedure for separation of watersoluble polysaccharides from brown seaweeds. Carbohydrate Research, 322(1999): 32-39. 